Rabaska

Revue d'ethnologie de l'Amérique française

\title{
Centre d'études acadiennes (Université de Moncton)
}

\section{Ronald Labelle}

Volume 3, 2005

URI : https://id.erudit.org/iderudit/201743ar

DOI : https://doi.org/10.7202/201743ar

Aller au sommaire du numéro

Éditeur(s)

Société québécoise d'ethnologie

ISSN

1703-7433 (imprimé)

1916-7350 (numérique)

Découvrir la revue

Citer ce document

Labelle, R. (2005). Centre d'études acadiennes (Université de Moncton).

Rabaska, 3, 204-205. https://doi.org/10.7202/201743ar d'utilisation que vous pouvez consulter en ligne.

https://apropos.erudit.org/fr/usagers/politique-dutilisation/ 


\section{Centre d'études acadiennes}

Université de Moncton

Moncton (N.-B.) E1A 3E9

Téléphone : (506) 858-4085

Télécopieur : (506) 858-4530

Activités du secteur folklore et ethnologie

\section{Numérisation des collections de folklore}

La numérisation des collections des archives de folklore du Céa progresse rapidement. Grâce à un don de la ville de Dieppe (N.-B.), il a été possible d'embaucher un spécialiste du traitement sonore afin de numériser plusieurs collections. Nous prévoyons qu'en juillet 2005, les importantes collections de Georges Arsenault, de Laurent Comeau et du père Anselme Chiasson seront numérisées en entier. Des copies seront conservées en mémoire informatique ainsi que sur des disques compacts de qualité archivistique. Bien entendu, les bandes audio originales seront aussi conservées. En ce qui concerne la collection Anselme Chiasson, un fichier numérique individuel est constitué pour chaque enregistrement, ce qui facilitera le repérage et la consultation, permettant en plus d'effectuer un choix de documents sonores pour l'intégration au site électronique du Centre d'études acadiennes.

\section{Obtention de copies de collections acadiennes}

Grâce à un financement spécial obtenu à l'Université de Moncton, le CÉA a conclu une entente avec les Archives de folklore de l'Université Laval pour l'obtention de copies numérisées de la majorité des collections acadiennes déposées à cette institution. Au cours du printemps 2005, trois grandes collections sont en voie d'être reproduites, soit celles de Dominique Gauthier, de Robert Bouthillier et Vivian Labrie, et de Luc Lacourcière. Une fois le travail complété, les chercheurs qui désirent connaître le vaste répertoire de contes et de chansons recueillis en Acadie n'auront qu'à se rendre au Centre d'études acadiennes. 
Archives de folklore

Les archives de folklore du CÉA se sont enrichies d'une centaine de collections au cours de l'année 2004-2005. La majorité constituent des travaux d'enquête complétés par les étudiants inscrits aux cours de littérature orale donnés par Marielle Cormier-Boudreau au Centre universitaire de Shippagan, un des satellites de l'Université de Moncton. Madame Cormier-Boudreau, qui a récemment terminé sa carrière de professeur à Shippagan, nous a légué des copies des collections constituées sous sa direction au cours des dernières années.

\section{Enseignement}

Ronald Labelle a dispensé les cours intitulés «Les genres de la littérature orale » et " Analyse des récits oraux » pendant l'année universitaire 20042005. Le département d'Études françaises propose maintenant la création de nouveaux cours portant entre autres sur les contes, les légendes et récits de croyance et sur l'étude de l'ethnologie en Amérique française. Toutefois, en raison du départ de Ronald Labelle et de l'absence d'un poste régulier d'enseignement de l'ethnologie au département d'Études françaises, aucun cours n'est offert dans le domaine pendant l'année 2005-2006.

RoNALD LABELLE 